\title{
Evaluation of a Thermodynamic Ice Crystal Icing Model Using Experimental Ice Accretion Data
}

\author{
Tadas P. Bartkus* \\ Ohio Aerospace Institute, Cleveland, $\mathrm{OH} 44142$, USA \\ Peter M. Struk ${ }^{\dagger}$ \\ NASA Glenn Research Center, Cleveland, OH, 44135, USA \\ and \\ Jen-Ching Tsao $\neq$ \\ Ohio Aerospace Institute, Cleveland, OH 44142, USA
}

\begin{abstract}
This paper presents the evaluation of a thermodynamic ice crystal icing model, previously presented to describe the possible mechanisms of icing within the core of a turbofan jet engine. It has been proposed that there are two types of distinct ice accretions based on a surface energy balance: freeze-dominated icing and melt-dominated icing. In the former, ice accretion occurs where a freeze fraction ( 0 to 1$)$ of melted ice crystals freezes on a surface, along with the existing ice of the impinging water and ice mass. This freeze-dominated icing is characterized by having strong adhesion to the surface. In the latter, icing occurs from accumulated unmelted ice on a surface, where a melt fraction ( 0 to 1$)$ dictates the amount of unmelted impinged ice. This melt-dominated icing is characterized by weakly bonded surface adhesion. The experimentally observed ice growth rates suggest that only a small fraction of the impinging ice remains on the surface, implying a mass loss mechanism such as splash, runback, bounce, or erosion. This mass loss parameter must be determined in conjunction with the fraction of freezing liquid water or fraction of melting ice on an icing surface. This loss parameter, however, along with the freeze and melt fraction, are the only experimental parameters that are currently not measured directly. Using reported icing growth rates from published ice crystal icing experiments, a methodology is proposed to determine these unknown parameters. This work takes reported ice accretion data from tests conducted by the National Aeronautics and Space Administration (NASA) in 2016 and tests NASA collaborated on with the National Research Council (NRC) of Canada in 2012 that examined the fundamental physics of ice crystal icing. Those research efforts sought to generate icing conditions representative of those that occur inside a jet engine when ingesting ice crystals. This paper presents the fundamental equations of the thermodynamic model, the methodology used to determine the aforementioned unknown icing parameters, and results from model evaluation using experimental data. In addition, this paper builds on the previously proposed model by adding a transient conduction term to explain ice growth behavior at the onset of experimental tests that was observed to be different from steady-state ice growth that occurred later in the test run. With the addition of this energy term, this becomes a quasi-steady model. A key finding from this work suggests that mass loss fractions can exceed 0.90 for steady ice growth periods. In addition, due to conductive heat fluxes when using a warmer-than-freezing airfoil, lower mass loss fraction values were calculated during the initial transient period.
\end{abstract}

\section{Nomenclature}

Cp = specific heat capacity $(\mathrm{J} / \mathrm{kg} / \mathrm{K})$

\footnotetext{
* Senior Research Associate, Icing Branch, 21000 Brookpark Road, MS 110-3, AIAA Member

† Aerospace Engineer, Icing Branch, 21000 Brookpark Road, MS 11-2, AIAA Senior Member

‡ Principal Research Scientist, Icing Branch, 21000 Brookpark Road, MS 11-2, AIAA Associate Fellow
} 


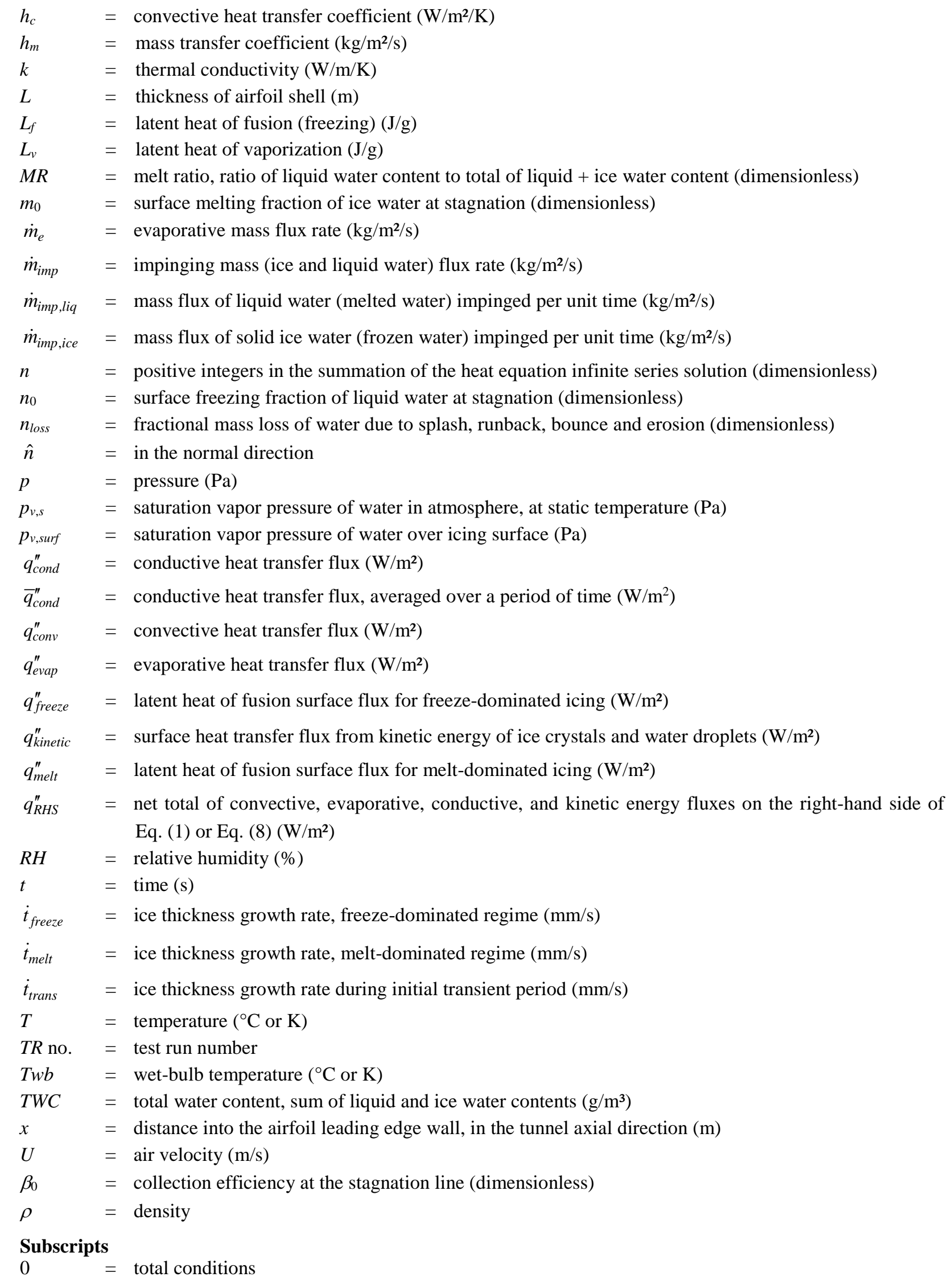




$\begin{array}{ll}\text { air } & =\text { air } \\ \text { cond } \rightarrow 0 & =\text { reference to time for conductive energy flux to reach } 1 \% \text { of total energy flux, a negligible amount } \\ e & =\text { end (or final) } \\ \text { i } & =\text { initial } \\ \text { ice } & =\text { ice } \\ \text { s } & =\text { static conditions } \\ \text { SS } & =\text { steady-state } \\ \text { surf } & =\text { icing surface } \\ \text { trans } & =\text { transient } \\ \text { wall } & =\text { wall, airfoil surface }\end{array}$

\section{Introduction}

There have been numerous reports of uncommanded turbofan engine power-loss events since the 1990s. Many events have been observed at altitudes at or above the upper limit at which water droplets can exist as liquid. These power loss events typically have occurred in deep convective updraft systems. The events have included engine stall, rollback, flameout, and damage to downstream components due to ice shedding. Mason et al. ${ }^{1}$ hypothesized that ice crystals ingested into the engine begin to partially melt within the compressor system and then, as a mixed-phase water mass, impinge and accrete on surfaces within the engine core. The hypothesis states the requirement of liquid water for ice accretion to occur. Furthermore, it was theorized that an optimum icing regime exists for ice crystal icing as a function of melt ratio, $M R$. It was hypothesized that an $M R$ region exists such that icing will not occur if there is not enough ice to cool the surface to the freezing point (i.e., too much liquid water) and where there is not enough liquid for the ice to stick (i.e., too little liquid water). It is between these two boundaries that ice crystal icing occurs. ${ }^{2}$

This threat of engine icing has spurred a substantial research effort in understanding the fundamental physics of ice crystal icing. To better understand the physical mechanisms of ice crystal icing, a series of tests has been conducted collaboratively between the National Aeronautics and Space Administration (NASA) and the National Research Council (NRC) of Canada at the Research Altitude Test Facility (RATFac) between 2010 and 2017. ${ }^{3-6}$ Independent research efforts by the two agencies has been undertaken as well. An initial study on the fundamentals of ice crystal icing physics was conducted at the NASA Propulsion Systems Laboratory (PSL) in 2016. ${ }^{7}$ In addition, the NRC investigated mixed-phase sticking efficiency, ${ }^{8}$ altitude scaling, ${ }^{9}$ and particle size effects ${ }^{10,11}$ related to ice crystal icing.

Currie et al. ${ }^{8}$ reported ice accretions that reached a steady-state size during a continuous exposure to a mixed-phase icing cloud. The steady-state ice shape was attributed to a balance between accretion and erosion. Currie developed a corresponding semi-empirical model of the accretions that introduced a concept called sticking efficiency. This is the fraction of an impinging mixed-phase water mass flux that is retained on the surface. The model treats the accretion process as strictly a sticking phenomenon, ignoring heat transfer, phase change, and runback.

In 2014, Tsao et al. ${ }^{12}$ proposed a simple thermodynamic model to describe the possible mechanisms for ice crystal icing on surfaces within a jet engine, which includes the factors not considered in Currie's work. The work stated that there are two distinct types of ice accretions based on an overall energy balance at the accretion site. The first type is freeze-dominated icing, characterized by liquid in a mixed-phase cloud freezing onto a surface along with ice present in the cloud. The amount of ice accretion is partially dictated by the freeze fraction, $n_{0}$, which is the mass fraction of liquid water that freezes. Freeze-dominated icing is characterized by strong adhesion to the surface. The second type is melt-dominated icing, whereby icing occurs from the remaining unmelted ice that accumulated on the surface. The amount of ice accumulation in melt-dominated icing is partially dictated by the melt fraction, $m_{0}$, which refers to the mass fraction of ice that melts. This type of icing is characterized by weakly bonded surface adhesion. Another key factor that dictates the amount of ice accretion is a mass loss presumably due to splash, runback, bounce, or erosion. Within the described icing mechanisms, to determine the mass fraction values of $n_{0}$ or $m_{0}$, a mass loss parameter, $n_{\text {loss }}$, must be determined. ${ }^{*}$ This mass loss fraction, along with the freeze and melt fraction, are the only experimental parameters that are currently not measured directly. Using reported icing growth rates from published ice crystal icing experiments, a methodology is proposed to determine these otherwise unknown parameters.

\footnotetext{
* To avoid confusion, it is important to recognize that melt ratio is different from melt fraction, despite similar wording. Melt ratio, $M R$, is the ratio of liquid water content to total water content. Melt fraction, $m_{0}$, refers to the fraction of ice that melts as determined by the thermodynamic energy balance at the icing surface.
} 
This work takes reported ice accretion data from tests conducted by NASA at the PSL in $2016^{7}$ and from tests NASA conducted collaboratively with the NRC at the RATFac in $2012^{4}$ to evaluate the thermodynamic model. This paper presents the main objectives of the research, the fundamental equations of the thermodynamic model, the methodology used to determine the aforementioned unknown icing parameters $\left(n_{0}, m_{0}\right.$, and $\left.n_{\text {loss }}\right)$, and results from model evaluation using experimental data. In addition, this paper builds on Tsao et al.'s model by adding a transient conduction term to explain ice growth behavior at the onset of experimental tests that was observed to be different from steady-state ice growth that occurred later in the test run.

\section{Objectives}

\section{A. Evaluation of Model Using Published Steady-State Ice Growth Rates}

The main objective of this work is to provide estimated values for the unknown parameters of $n_{\text {loss }}$ and $n_{0}$ or $m_{0}$ in the ice crystal icing thermodynamic model proposed by Tsao et al. ${ }^{12}$ These parameters will be determined by utilizing experimental ice accretion data reported by NASA and the NRC in 2012 and NASA in 2016. The ice growth rates will be taken from steady-state growth leading edge ice accretions after an initial transient. It is desired to better understand if there is an optimal melt ratio, $M R$, for ice crystal icing as previously hypothesized. ${ }^{2}$

\section{B. Initial Transient Conduction Development and Model Evaluation}

Previous experimental work ${ }^{4,7}$ has shown that there is an initial ice growth rate during the initial moments of ice cloud activation (within approximately the first 10 or 20 s) that is different than the steady-state ice growth rates that occur later in the spray duration. For these early icing growth rates, a transient conduction energy flux term is introduced and added to the thermodynamic model proposed by Tsao et al. ${ }^{12}$ The model will be evaluated with this new term by using the experimental initial ice growth rates. The resulting $n_{\text {loss }}$ and $n_{0}$ or $m_{0}$ values will also be analyzed.

\section{Thermodynamic Model for Ice Crystal Icing Description}

This thermodynamic model for ice crystal icing within jet engines was proposed by Tsao et al. ${ }^{12}$ The model was primarily based on scaling work for super-cooled liquid water icing, originally done by Ruff, ${ }^{13}$ which was later extended by Anderson ${ }^{14}$ and Anderson and Tsao. ${ }^{15}$ Please refer to these works for physical descriptions and detailed derivations of the parameters.

\section{A. Model Assumptions}

The following assumptions are listed for this thermodynamic model:

- Air flow is steady relative to the accretion process.

- Accretion is at the stagnation point of an airfoil.

- All water mass comes from the impinging water or ice cloud, and no mass comes from any water flow from neighboring surface control volumes. Hence, any energy exchange related to surface water flow is neglected.

- All impinging water mass is assumed to be at the freezing temperature of water $\left(0^{\circ} \mathrm{C}\right)$, whether the water mass is all liquid, all ice, or mixed phase. Therefore, energy expressions related to the sensible energy of the water mass are neglected.

- Coefficients of heat and mass transfer, as initially measured on a non-iced airfoil surface, remain constant despite changing geometries as ice accretes on the airfoil leading edge.

- Heat transfer due to radiation is negligible and neglected.

\section{B. Surface Energy Balance Equations}

According to Tsao et al., ${ }^{12}$ there are two distinct mechanisms for ice crystal icing growth. These are noted as freeze-dominated icing and melt-dominated icing. The conservation of energy expressions for the icing surface for both mechanisms are discussed below.

\section{Freeze-Dominated Regime}

The general energy conservation law at the icing surface for freeze-dominated icing is shown in Eq. (1). This expression, with respect to the sign convention, assumes that the net energy transfer from the right-hand side of the equation is positive. Hence, the left-hand side is also positive and represents the flux that goes into the freezing process, or the latent heat of fusion for freezing, $q_{\text {freeze }}^{\prime \prime}$. In the expression, $q_{\text {evap }}^{\prime \prime}$ is the evaporative heat transfer flux (heat 
transferred away from icing surface = positive), $q_{\text {conv }}^{\prime \prime}$ is the convective heat transfer flux (heat to icing surface $=$ positive), $q_{\text {kinetic }}^{\prime \prime}$ is the kinetic energy transfer flux (energy into icing surface = positive), and $q_{\text {cond }}^{\prime \prime}$ is the conductive heat transfer flux (heat to icing surface = positive). These energy flux terms are further described in greater detail in the following paragraphs.

$$
q_{\text {freeze }}^{\prime \prime}=q_{\text {evap }}^{\prime \prime}-q_{\text {conv }}^{\prime \prime}-q_{\text {kinetic }}^{\prime \prime}-q_{\text {cond }}^{\prime \prime}
$$

The evaporative heat transfer flux at the icing surface is shown in Eq. (2). In the expression, $\dot{m}_{e}$ is the evaporative mass flux rate and $L_{v}$ is the latent heat of vaporization. It should be noted that ice on the surface will sublimate and water will evaporate, so the value of $L_{v}$ will be dependent on the mixture (quality) of ice and liquid water. The evaporative mass flux rate term can be expressed in terms of an evaporative mass transfer coefficient, $h_{m}$, total temperature, $T_{0}$, static temperature, $T_{\mathrm{s}}$, total pressure, $p_{0}$, static pressure, $p_{s}$, saturation vapor pressure of water in air, $p_{v, s}$, the saturation vapor pressure of water at the icing surface, $p_{v, \text { surf }}$ and the static relative humidity, $R H_{s}$. The term in parentheses in Eq. (2) accounts for the compressibility of the flowing air.

$$
q_{\text {evap }}^{\prime \prime}=\dot{m}_{e} L_{v}=h_{m}\left(\frac{\frac{p_{v, \text { surf }}}{T_{s}}-\frac{p_{0}}{T_{0}} \cdot \frac{p_{v, s}}{p_{s}} \cdot R H_{s}}{\frac{1}{0.622} \cdot \frac{p_{0}}{T_{0}}-\frac{p_{v, \text { surf }}}{T_{s}}}\right) L_{v}
$$

The convective heat transfer flux at the icing surface is shown in Eq. (3). In the expression, $h_{c}$, is the convective heat transfer coefficient, $U$, is the air velocity, $C p_{\text {air }}$, is the specific heat capacity of air, and $T_{\text {surf }}$ is the icing surface temperature. The value of $T_{\text {surf }}$ is generally $0{ }^{\circ} \mathrm{C}$, as this model is concerned with the mixed-phase regime of water. The sum of the first two terms within the parentheses of Eq. (3) is equivalent to the total air temperature.

$$
q_{\text {conv }}^{\prime \prime}=h_{c}\left(T_{s}+\frac{U^{2}}{2 C p_{\text {air }}}-T_{\text {surf }}\right)
$$

The kinetic energy transfer flux at the icing surface is shown in Eq. (4). In the expression, $\dot{m}_{i m p}$, is the impinging mass flux rate, and $U$ is the velocity of the impinging mass (which is equal to the air velocity). The value of $\dot{m}_{i m p}$ can be expressed in terms of total water content, TWC, collection efficiency at the stagnation line, $\beta_{0}$, particle mass velocity, and mass remaining on the icing surface after all losses, $n_{\text {loss }}$, due to splash, runback, bounce, and erosion are accounted for. In this form, the equation neglects any kinetic energy transfer from mass loss from the impinging water.

$$
q_{\text {kinetic }}^{\prime \prime}=\dot{m}_{\text {imp }} \cdot \frac{U^{2}}{2}=T W C \cdot \beta_{0} \cdot U\left(1-n_{\text {loss }}\right) \cdot \frac{U^{2}}{2}
$$

The conduction heat transfer flux to the icing surface is shown in Eq. (5). In the expression, $k_{\text {wall }}$ is the thermal conductivity of the airfoil surface, and the $d T / d \hat{n}$ term refers to the change in temperature in the normal direction within the airfoil at the ice and airfoil interface $(\hat{n}=0)$. Heat transfer from the wall to the water and ice mix is positive in value, according the sign notation in Eq. (5). It should be noted that the conduction term as currently presented is in steady-state form. A detailed description in calculating the value of the temperature rate of change term and how this value is handled as steady-state is provided in Section III.D. This conduction energy flux term is not listed in the paper by Tsao et al. ${ }^{12}$ and is a new addition to the thermodynamic model.

$$
\left.q_{\text {cond }}^{\prime \prime}=k_{\text {wall }} \frac{d T}{d \hat{n}}\right]_{\text {wall }}
$$

The latent heat of fusion surface flux for freeze-dominated icing is shown in Eq. (6). In the expression, $\dot{m}_{i m p, l i q}$ is the mass flux rate of liquid water, $n_{0}$ the freeze mass fraction, and $L_{f}$ is the latent heat of fusion. The value of $\dot{m}_{i m p, l i q}$ can be expressed in terms of total water content, melt ratio, collection efficiency at the stagnation line, particle mass 
velocity, and mass remaining on the icing surface after all losses due to splash, runback, bounce, and erosion are accounted for.

$$
q_{\text {freeze }}^{\prime \prime}=\dot{m}_{\text {imp,liq }} \cdot n_{0} \cdot L_{f}=(T W C \cdot M R) \beta_{0} \cdot U\left(1-n_{\text {loss }}\right) n_{0} \cdot L_{f}
$$

Freeze-dominated icing focuses on the fraction of liquid water that can freeze, $n_{0}$. Equations (1) and (6) can be combined and arranged for $n_{0}$, and this is shown in Eq. (7).

$$
n_{0}=\frac{q_{\text {evap }}^{\prime \prime}-q_{\text {conv }}^{\prime \prime}-q_{\text {kinetic }}^{\prime \prime}-q_{\text {cond }}^{\prime \prime}}{\dot{m}_{\text {imp }, \text { liq }} \cdot L_{f}}
$$

The individual energy fluxes in the numerator of Eq. (7) can be substituted with the respective expression from Eq. (2) through Eq. (5), respectively. It should be noted that liquid mass must initially be present for freeze-dominated icing to occur. In addition, it should be noted that Eq. (7) is a function of $n_{\text {loss. }}$.

\section{Melt-Dominated Regime}

As previously noted, the value of $q_{\text {freeze }}^{\prime \prime}$ will be positive in the freeze-dominated regime. If the sum of the terms on the right side of Eq. (1) is negative, then melt-dominated freezing is possible. This is explicitly expressed in Eq. (8), where $q_{\text {melt }}^{\prime \prime}$ is the latent heat of fusion surface flux for melt-dominated icing. According to the sign convention in Eq. (8), the value of $q_{\text {melt }}^{\prime \prime}$ is positive for melt-dominated icing.

$$
q_{\text {melt }}^{\prime \prime}=q_{\text {conv }}^{\prime \prime}+q_{\text {kinetic }}^{\prime \prime}+q_{\text {cond }}^{\prime \prime}-q_{\text {evap }}^{\prime \prime}
$$

The individual energy fluxes on the right-hand side of Eq. (8) are identical as expressed in the previous Freeze-Dominated Regime section. The value of $q_{m e l t}^{\prime \prime}$ can be expressed in terms of the impinging ice mass flux rate, $\dot{m}_{i m p, i c e}$, the ice mass melt fraction, $m_{0}$, and the latent heat of fusion, $L_{f}$, and is shown in Eq. (9).

$$
q_{\text {melt }}^{\prime \prime}=\dot{m}_{\text {imp,ice }} \cdot m_{0} \cdot L_{f}=T W C(1-M R) \beta_{0} \cdot U\left(1-n_{\text {loss }}\right) m_{0} \cdot L_{f}
$$

Melt-dominated icing focuses on the fraction of ice that can melt, $m_{0}$. Equations (8) and (9) can be combined and arranged for $m_{0}$, and this is shown in Eq. (10).

$$
m_{0}=\frac{q_{\text {conv }}^{\prime \prime}+q_{\text {kinetic }}^{\prime \prime}+q_{\text {cond }}^{\prime \prime}-q_{\text {evap }}^{\prime \prime}}{\dot{m}_{\text {imp,ice }} \cdot L_{f}}
$$

It should be noted that ice mass must initially be present for melt-dominated icing to occur. Similar to the freeze mass fraction expression in Eq. (7), the melt mass fraction expression in Eq. (10) is also a function of $n_{\text {loss. }}$.

\section{Stagnation Icing Growth Rates}

All parameters can be measured experimentally except for $\beta_{0}, n_{\text {loss }}$, and $n_{0}$ Eq. (7) and $m_{0}$ in Eq. (10). Values of $\beta_{0}$ are dependent on particle size, velocity, and airfoil geometry and can be approximated using simulation. ${ }^{16}$ For this analysis, the collection efficiency value will be approximated to be unity, $\beta_{0}=1$. This leaves $n_{\text {loss }}$ as the only unknown for determining either $n_{0}$ or $m_{0}$. The rates of ice growth can be used to help determine these values of freeze or melt fraction. The icing growth rates are expressed for freeze-dominated icing, $\dot{t}_{\text {freeze }}$, in Eq. (11) and melt-dominated icing, $\dot{t}_{\text {melt }}$, in Eq. (12). The units of ice growth rates are in terms of distance over time.

$$
\begin{gathered}
\dot{t}_{\text {freeze }}=\frac{\dot{m}_{\text {imp }, \text { liq }} \cdot n_{0}+\dot{m}_{\text {imp }, \text { ice }}}{\rho_{\text {ice }}} \cdot\left(1-n_{\text {loss }}\right) \\
\dot{t}_{\text {melt }}=\frac{\dot{m}_{\text {imp }, \text { ice }}\left(1-m_{0}\right)}{\rho_{\text {ice }}} \cdot\left(1-n_{\text {loss }}\right)
\end{gathered}
$$




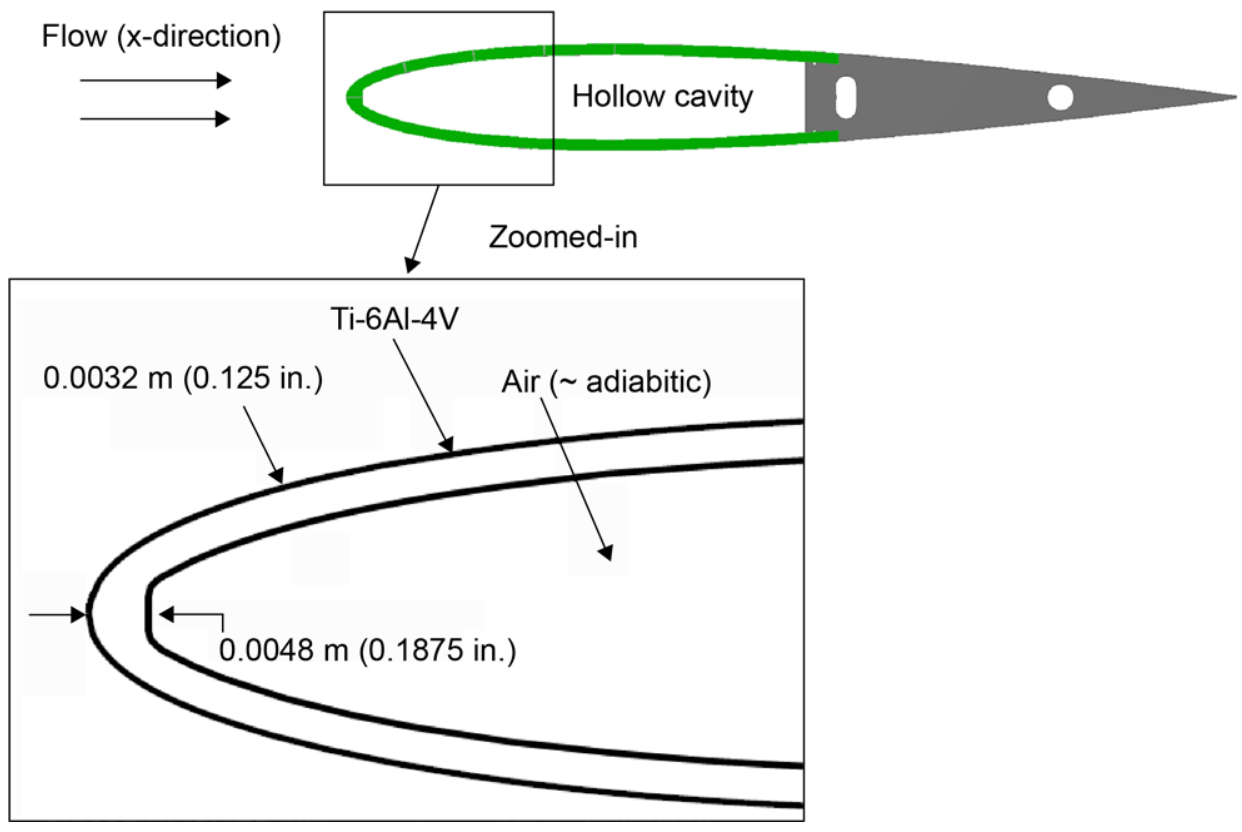

Fig. 1. Zoomed-in front portion of a NACA 0012 airfoil including dimensions. The airfoil shell (green) is made of titanium alloy Ti-6Al-4V. The airfoil chord length is $0.267 \mathrm{~m}$ (10.5 in).

In the above expressions, $\rho_{\text {ice }}$ is the density of ice. In Eq. (11), all of the ice mass along with water mass that freezes, after losses, contributes to the ice growth. In Eq. (12), it is ice mass that has not melted, after losses, that contributes to ice growth. Ice growth rates have been measured experimentally, therefore providing values for $\dot{t}_{\text {freeze }}$ and $\dot{t}_{\text {melt }}$ depends on the type of icing. For freeze-dominated icing, Eq. (7) and Eq. (11) can be solved together, providing values for $n_{\text {loss }}$ and $n_{0}$. For melt-dominated icing, Eq. (10) and Eq. (12) can be solved together, providing values for $n_{\text {loss }}$ and $m_{0}$, respectively. The unknown values cannot be solved for directly, but can be determined by using an iterative solving method.

\section{Conduction ( $q_{\text {cond }}^{\prime \prime}$ ) Derivation}

Conduction between the wall (airfoil leading edge) and the incoming water and ice mass is inherently a transient problem. As an example, as cold water or ice comes in contact with a warm wall surface, the temperature of the wall will decrease in temperature with respect to time as heat is conducted from the wall to the water and ice mass. As the temperature in the wall approaches the water and ice mass temperature, $q_{\text {cond }}^{\prime \prime}$ decreases until it reaches a value of 0 , representing conductive steady-state.

Experimental data of ice accretion on a National Advisory Committee for Aeronautics (NACA) 0012 airfoil were collected. These ice growth rates are used for this thermodynamic model evaluation. Figure 1 shows a zoomed-in view of the front half of the NACA 0012 airfoil ( $0.267 \mathrm{~m}$ (10.5 in) chord length), which includes the dimensions of the airfoil. The airfoil shell is made of titanium alloy Ti-6Al-4V, whereas the interior is filled with air and can be approximated as adiabatic.

To simplify the transient conduction at the airfoil leading edge, the geometry of the NACA 0012 airfoil is approximated as a one-dimensional (1D) plane wall. Since the tests were conducted with an airfoil at $0^{\circ}$ angle of attack, the normal direction, $\hat{n}$, at the leading edge of the airfoil will be represented by the variable $x$, representing the tunnel axial direction. Therefore, the general expression for a 1D transient conductive heat transfer expression at the airfoil leading edge is shown in Eq. (13).

$$
\rho_{\text {wall }} C p_{\text {wall }} \frac{\partial T}{\partial t}=k_{\text {wall }} \frac{\partial^{2} T}{\partial x^{2}}
$$




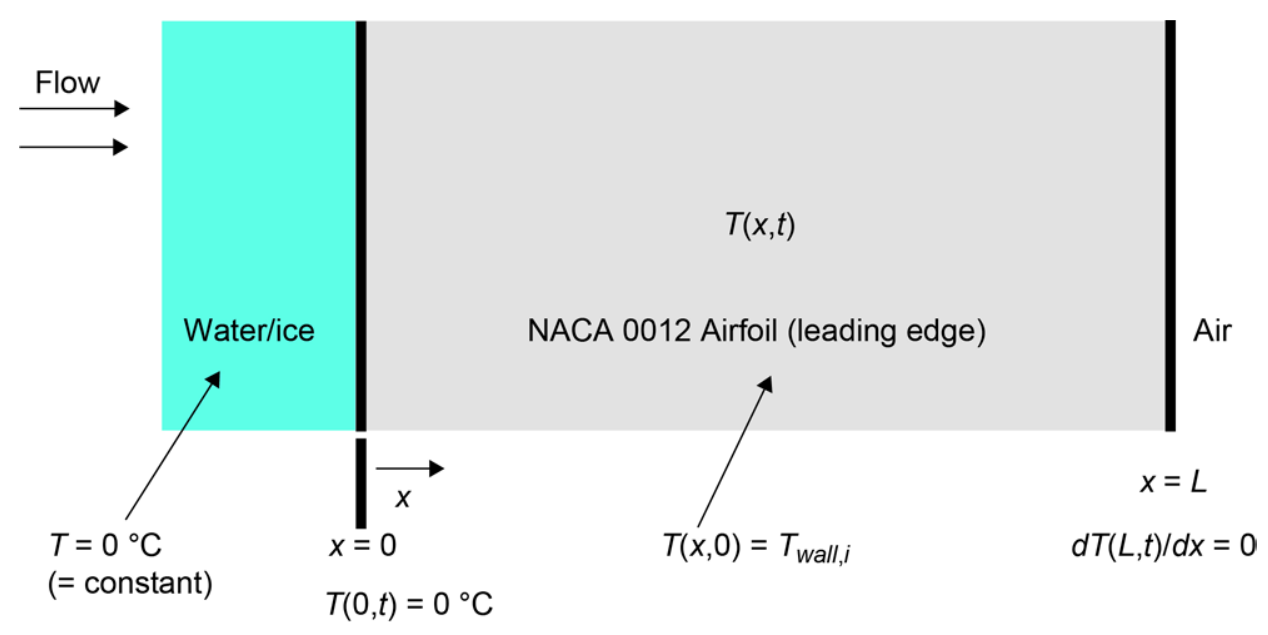

Fig. 2. Simplified 1D depiction of the leading edge of the NACA 0012 airfoil with initial and boundary conditions. At the airfoil leading edge, the normal direction (tunnel axial direction) is represented by $x$.

In the above expression, $\rho_{\text {wall }}$ is the wall density, $C p_{\text {wall }}$ is the wall specific heat, and $k_{\text {wall }}$ is the wall thermal conductivity, which is approximated to be constant. Temperature is a function of distance into the wall ( $x$ ) and time $(t)$, and can be expressed generally as $T(x, t)$. The thermal conductivity heat flux into the water and ice mass for a particular moment can be determined by solving for $T$ and calculating the spatial change in temperature at the ice and wall interface ( $d T / d x$ at $x=0)$. Analytical solutions can be determined for transient heat diffusion when boundary conditions (two needed) and initial conditions (one needed) are provided. Figure 2 depicts this 1D transient conduction as water and ice come into contact with the leading edge of the airfoil. Since a mixed-phase water and ice mass is at a constant temperature of $T=0{ }^{\circ} \mathrm{C}$, the boundary condition at the wall and ice interface $(x=0)$ remains constant for all time $t$, and can be expressed as $T(0, t)=0$. The interior of the airfoil is filled with air, so the boundary condition at the airfoil shell interior $(x=L)$ can be approximated as adiabatic. This means that there is no temperature gradient at this internal boundary and this can be expressed as $\partial T(L, t) / \partial x=0$. Prior to water or ice impacting the airfoil leading edge, the general initial airfoil temperature across the airfoil wall thickness is $T_{\text {wall,i. }}$ In the experiments conducted, the airfoil was exposed to flowing air and can be approximated to be at the total air temperature, $T_{0}$. The entire thickness is approximated to be initially uniform in temperature and therefore, the initial condition can be expressed as $T(x, 0)=$ $T_{\text {wall, } i}=T_{0}$. Analytical solutions for $T(x, t)$ in Eq. (13) can be determined given these two boundary conditions and initial condition (approximating $T_{\text {wall, } i}$ as uniform) by using Separation of Variables and Fourier Series methods. ${ }^{17}$ The solution for $T(x, t)$ is an infinite series and is expressed in Eq. (14).

$$
T(x, t)=\frac{4 T_{\text {wall }, i}}{\pi} \sum_{n=1}^{\infty} \frac{\sin \left[(2 n-1) \frac{\pi x}{2 L}\right] \cdot e^{-\left[\frac{(2 n-1)^{2} \pi^{2} k_{\text {wall }}}{4 L^{2} \rho_{\text {wall }} C p_{\text {wall }}}\right] t}}{2 n-1}
$$

In Eq. (14), $n$ represents the positive integers in the summation of this infinite series solution. Transient temperature profiles can be calculated when the airfoil physical properties are used. The physical properties for titanium alloy Ti-6Al-4V include $\rho_{\text {wall }}=4,470 \mathrm{~kg} / \mathrm{m}^{3}, k_{\text {wall }}=7.2 \mathrm{~W} /(\mathrm{m} \bullet \mathrm{K})$, and $C p_{\text {wall }}=562 \mathrm{~J}(\mathrm{~kg} \cdot \mathrm{K})$. These three properties are approximated to be constant. Figure 3 shows temperature profile solutions for the first $6 \mathrm{~s}$ after a step change is introduced at $x=0$, using these physical material properties and a uniform initial temperature of $T_{\text {wall,i. }}$. A temperature profile is shown at intervals of $0.1 \mathrm{~s}$. The temperature has been non-dimensionalized on the y-axis ([T - $\left.T_{\text {surf }}\right] /$ [ $\left.T_{\text {wall,i }}-T_{\text {surf }}\right]$ ), where $T_{\text {surf }}$ is the icing surface temperature, which is at $0{ }^{\circ} \mathrm{C}$. In addition, the wall location has been normalized by the thickness of the airfoil shell, $L$, on the $\mathrm{x}$-axis. The figure shows the decaying temperature profiles as the temperatures within the airfoil leading edge wall approach the water and ice temperature of $T=0{ }^{\circ} \mathrm{C}$. These 


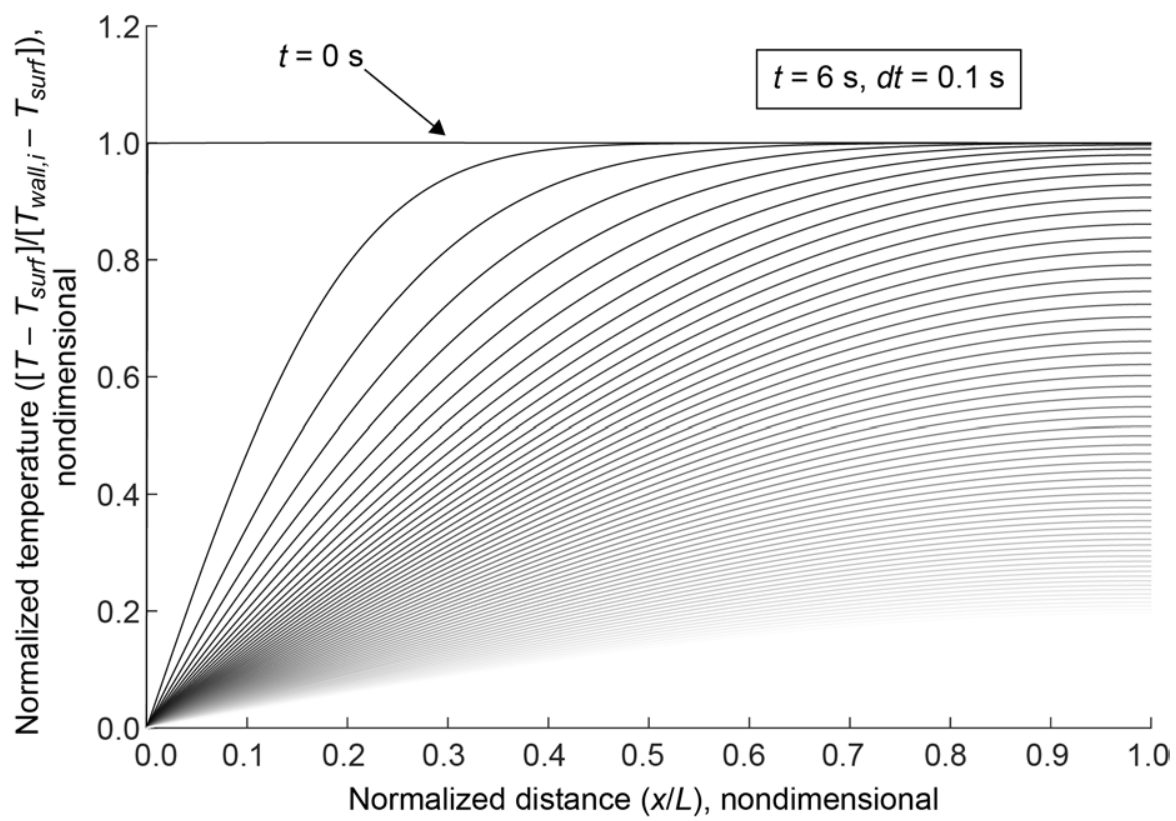

Fig. 3. Normalized temperature profile solutions for 1D transient heat conduction within the airfoil leading edge wall. The first $6 \mathrm{~s}$ of conduction are shown with $0.1 \mathrm{~s}$ intervals. The solutions are specifically for titanium alloy $\mathrm{Ti}$ $6 \mathrm{Al}-4 \mathrm{~V}$ with physical properties of $\rho_{\text {vall }}=4,470 \mathrm{~kg} / \mathrm{m}^{3}, \mathrm{k}_{\text {wall }}=7.2 \mathrm{~W} /(\mathrm{m} \cdot \mathrm{K})$, and $C p_{\text {wall }}=562 \mathrm{~J} /(\mathrm{kg} \cdot \mathrm{K})$. A value of $n=100,000$ was used with respect to the summation term in Eq. (14) to produce the temperature profiles.

temperature profiles in Fig. 3 will look similar, regardless of whether $T_{\text {wall }, i}$ is greater than or less than the water and ice temperature of $T=0^{\circ} \mathrm{C}$.

With temperature profile solutions available, the conductive heat flux into the water and ice mass can be determined by the change in temperature with respect to $x$ at $x=0$ for any time $t$. Figure 4 shows the instantaneous transient conductive heat flux when normalized by the initial wall temperature, $T_{\text {wall, } i}$ (blue, dashed trace). The conductive heat flux is initially large and decays with respect to time. It can be seen that after about $20 \mathrm{~s}$, the normalized conductive heat flux becomes quite small and conduction can potentially be neglected as the entire airfoil wall temperature approaches $T=0{ }^{\circ} \mathrm{C}$. Conductive heat transfer plays a more significant role in the initial moments. Whereas conductive heat flux is transient and fairly variable during the first moments, a running average conductive heat flux is calculated to approximate the flux in a single value (red solid trace in Fig. 4). This running average is simply the average cumulative energy for any given time period starting at $t=0 \mathrm{~s}$. This single value of conductive heat flux is desired since single values of experimental initial ice accretion rates were reported. These reported rates were generally measured spanning the first several seconds of a test run. Therefore, a running average conductive heat flux value is used to approximate the conductive heat flux that transpired during the first several seconds during each experiment run. For example, if an initial ice accretion rate was reported for the first $5 \mathrm{~s}$, the corresponding average conductive heat flux for that 5-s period would be the running average value of $1,915 \mathrm{~W} /\left(\mathrm{m}^{2} \cdot \mathrm{K}\right)$ multiplied by the airfoil initial temperature of $T_{\text {wall,i. }}$. For clarity, the instantaneous conductive heat flux is represented by $q_{\text {cond }}^{\prime \prime}$, whereas the average conductive heat flux for a determined period of time is represented by $\bar{q}_{\text {cond }}^{\prime \prime}$. 


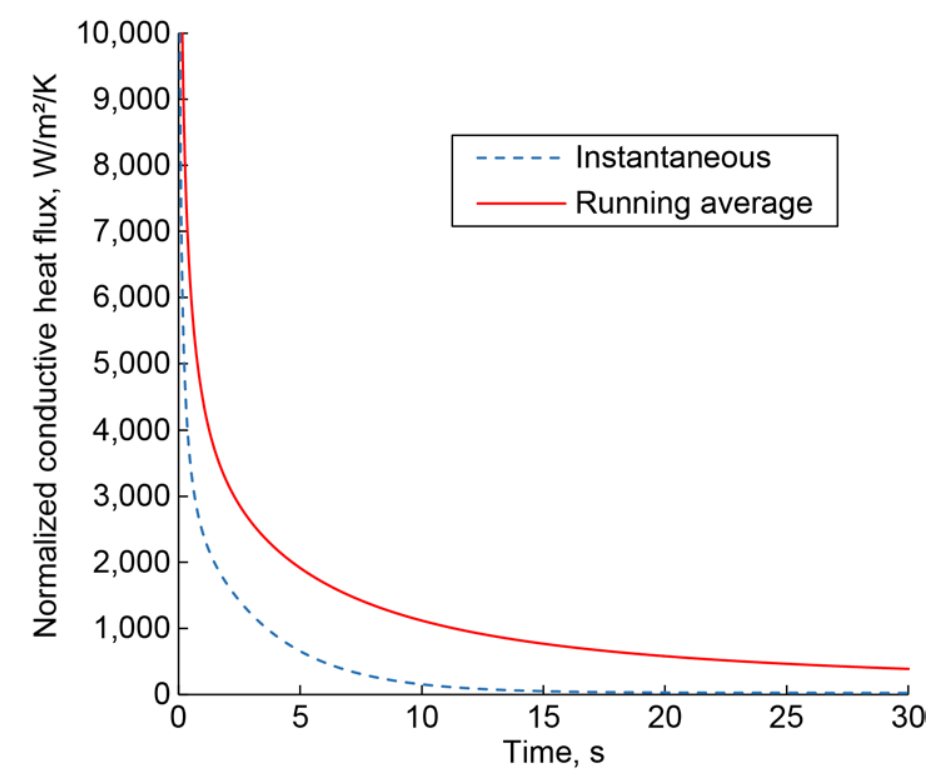

Fig. 4. Instantaneous and running average transient conductive heat flux values, normalized by initial temperature, $\boldsymbol{T}_{\text {wall,i. }}$

\section{Model Results}

Results from using the thermodynamic model are presented here. This includes a sample parametric study of the model as well as comparison of the model with experimental data from the 2012 NRC RATFac and 2016 NASA PSL testing.

\section{A. Model Parametric Study}

A sample parametric study is provided to illustrate model behavior and results. In this example, icing at the leading edge of a NACA 0012 airfoil with a $0.267 \mathrm{~m}$ (10.5 in) chord is modeled. The parameters in this sample study, which are representative of actual conditions, are shown in Table 1 , and are held constant, including $n_{\text {loss. }}$. Since $n_{\text {loss }}$ is known in this sample study, it is the ice growth rate $\left(\dot{t}_{\text {freeze }}\right.$ or $\left.\dot{t}_{\text {melt }}\right)$ that we solve for, including the freeze fraction or melt fraction. For simplicity, the conduction energy flux is neglected in this sample $\left(q_{c o n d}^{\prime \prime}=0 \mathrm{~W} / \mathrm{m}^{2}\right)$. Convective heat transfer and mass transfer correlations are used from Anderson and are shown in Table $1 .^{14}$

Table 1: Parameters held constant for the sample model study.

\begin{tabular}{|c|c|c|c|c|c|c|c|c|c|}
\hline $\begin{array}{c}T W C, \\
\mathrm{~g} / \mathrm{m}^{3}\end{array}$ & $M R$ & $\begin{array}{c}U, \\
\mathrm{~m} / \mathrm{s}\end{array}$ & $\begin{array}{c}p_{s}, \\
\mathrm{kPa}\end{array}$ & $\begin{array}{c}T_{s}, \\
{ }^{\circ} \mathrm{C}\end{array}$ & $\begin{array}{c}T_{\text {surf, }} \\
{ }^{\circ} \mathrm{C}\end{array}$ & $n_{\text {loss }}$ & $\begin{array}{c}q_{\text {cond }}^{\prime \prime}, \\
\mathrm{W} / \mathrm{m}^{2}\end{array}$ & $\begin{array}{c}h_{c}, \\
\mathrm{~W} /\left(\mathrm{m}^{2} \cdot \mathrm{K}\right)\end{array}$ & $\begin{array}{c}h_{m}, \\
\mathrm{~kg} /\left(\mathrm{m}^{2 \cdot} \mathrm{s}\right)\end{array}$ \\
\hline 3.84 & 0.31 & 82.3 & 42.7 & -0.8 & 0.0 & 0.937 & 0 & 355 & 0.251 \\
\hline
\end{tabular}

Freeze mass fraction, melt mass fraction, and the ice growth rate are shown for varying relative humidities in Fig. 5. Studying the figure, it can be seen that when relative humidity is varied from 0 to $50 \%$, the freeze fraction is constant with a value of $n_{0}=1$ and icing is freeze dominated. This means that all of the liquid mass in the mixed-phase water mass $(M R=0.31)$ freezes after losses. This results in an ice growth rate of $\dot{t}_{\text {freeze }}=0.022 \mathrm{~mm} / \mathrm{s}$ for that range of $R H_{s}$. As $R H_{s}$ increases from 50 to 85.6\%., the freeze fraction decreases in a linear fashion from $n_{0}=1$ to $n_{0}=0$. The ice growth rate decreases during this range because there is less water mass that is freezing. At $R H_{s}=85.6 \%$, no water mass is freezing and no ice mass is melting. The ice growth rate is simply the contribution of ice in the initial impinging mixed-phase mass. This is the transition point from freeze-dominated icing to melt-dominated icing. As $R H_{s}$ increases above $85.6 \%$, melt-dominated icing exists and the melt fraction begins to increase to a maximum value of $m_{0}=0.18$ at $R H_{s}=100 \%$. The ice growth rate continues to decrease to a value of $\dot{t}_{\text {melt }}=0.012 \mathrm{~mm} / \mathrm{s}$ at $R H_{s}=100 \%$. This continuous decrease in ice growth rate as $R H_{s}$ increases is because there is less ice remaining from the impinging mass due to increased melting. 


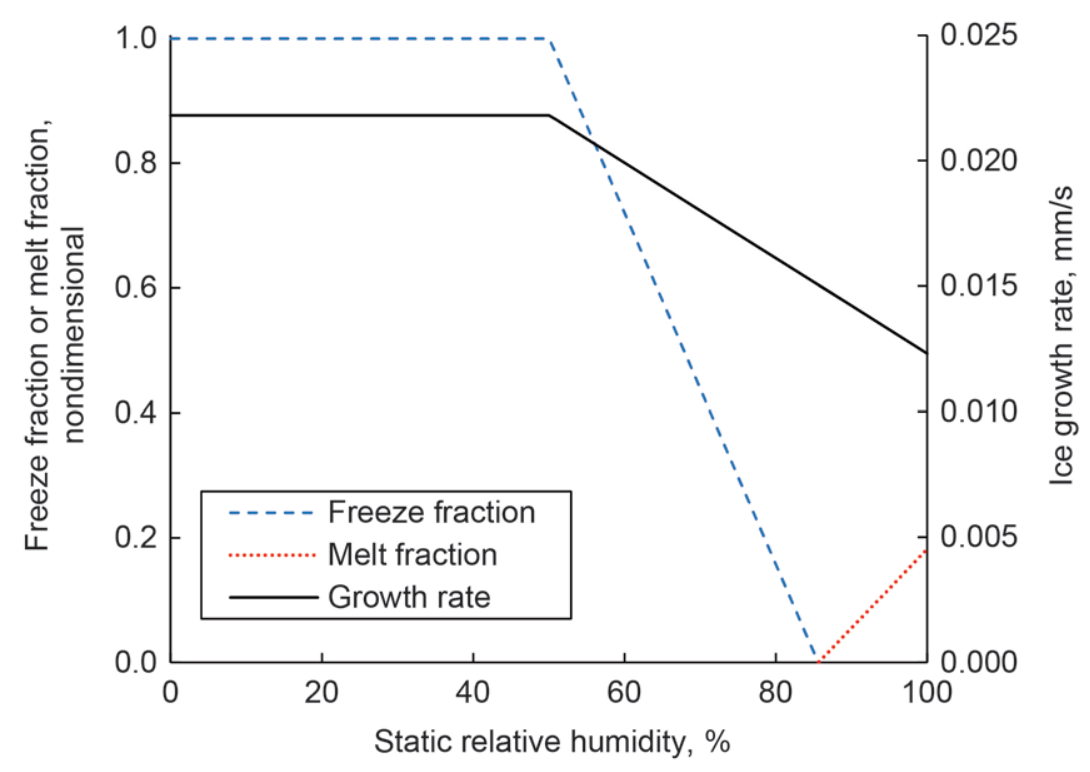

Fig. 5. Freeze fraction, melt fraction, and ice growth rate plotted for varying relative humidities for a sample study.

As the value of $R H_{s}$ decreases from $50 \%$, the capacity to freeze even more liquid water exists. This is shown in Table 2, which lists details of energy fluxes and other model parameters for various $R H_{s}$ values. For example, when $R H_{s}=0 \%$, the total of the evaporative, convective and kinetic energy fluxes on the right-hand side of Eq. (1), $q_{R H_{s}}^{\prime \prime}$, equals $4,971 \mathrm{~W} / \mathrm{m}^{2}$, whereas $q_{\text {freeze }}^{\prime \prime}=2,064 \mathrm{~W} / \mathrm{m}^{2}$. This $q_{\text {freeze }}^{\prime \prime}$ value represents the maximum value for this sample case and for this given $n_{\text {loss }}$ value, as all the water is frozen $\left(n_{0}=0\right)$. The value of $q_{R H_{s}}^{\prime \prime}$ exceeds the value of $q_{\text {freeze }}^{\prime \prime}$ until $R H_{s}$ reaches approximately $50 \%$ and is the reason why the capacity to freeze even more liquid water exists in this 0 to $50 \% R H_{s}$ range. When no more energy can be extracted from the latent energy phase change of water, then this situation would suggest that sensible energy can be removed from the frozen ice. In other words, the ice temperature has the potential to decrease below $0{ }^{\circ} \mathrm{C}$. For these conditions, the ice temperature at the stagnation point would continue to decrease below $0{ }^{\circ} \mathrm{C}$ until it reached the thermodynamic equilibrium temperature of $T w b_{0}$.

Table 2: Details of energy fluxes and other model parameters in the sample study where $R_{H}$ is varied. Energy values are listed according to sign notation of Eq. (1) if freeze-dominated or Eq. (2) if melt-dominated.

\begin{tabular}{|r|r|c|c|c|c|c|c|c|c|c|c|c|}
\hline $\begin{array}{c}R H_{s}, \\
\%\end{array}$ & $\begin{array}{c}q_{\text {evap }}^{\prime \prime}, \\
\mathrm{W} / \mathrm{m}^{2}\end{array}$ & $\begin{array}{c}q_{\text {conv }}^{\prime \prime} \\
\mathrm{W} / \mathrm{m}^{2}\end{array}$ & $\begin{array}{c}q_{\text {kinetic }}^{\prime \prime}, \\
\mathrm{W} / \mathrm{m}^{2}\end{array}$ & $\begin{array}{c}q_{R H S}^{\prime \prime}, \\
\mathrm{W} / \mathrm{m}^{2}\end{array}$ & $\begin{array}{c}q_{\text {freze }}^{\prime \prime} \\
\mathrm{W} / \mathrm{m}^{2}\end{array}$ & $\begin{array}{c}q_{\text {melt }}^{\prime \prime}, \\
\mathrm{W} / \mathrm{m}^{2}\end{array}$ & $\begin{array}{c}\text { Condition, } \\
\text { melt/ } \\
\text { freeze }\end{array}$ & $n_{0}$ & $m_{0}$ & $\begin{array}{c}\dot{t}_{\text {freze }}, \\
\mathrm{mm} / \mathrm{s}\end{array}$ & $\begin{array}{c}\dot{t}_{\text {melt }}, \\
\mathrm{mm} / \mathrm{s}\end{array}$ & $\begin{array}{c}T w b_{0}, \\
{ }^{0} \mathrm{C}\end{array}$ \\
\hline 0.0 & 5,962 & 923 & 68 & 4,971 & 2,064 & N/A & Freeze & 1.00 & N/A & 0.022 & N/A & -8.2 \\
\hline 25.0 & 4,510 & 923 & 68 & 3,519 & 2,064 & N/A & Freeze & 1.00 & N/A & 0.022 & N/A & -5.6 \\
\hline 50.0 & 3,058 & 923 & 68 & 2,067 & 2,064 & N/A & Freeze & 1.00 & N/A & 0.022 & N/A & -3.2 \\
\hline 51.0 & 3,000 & 923 & 68 & 2,009 & 2,009 & N/A & Freeze & 0.97 & N/A & 0.022 & N/A & -3.1 \\
\hline 77.5 & 1,460 & 923 & 68 & 470 & 470 & N/A & Freeze & 0.23 & N/A & 0.017 & N/A & -0.9 \\
\hline 85.6 & 993 & 923 & 68 & 2 & 2 & N/A & Freeze & 0.001 & N/A & 0.015 & N/A & -0.3 \\
\hline 85.7 & 986 & 923 & 68 & 5 & N/A & 5 & Melt & N/A & 0.001 & N/A & 0.015 & -0.3 \\
\hline 89.3 & 777 & 923 & 68 & 214 & N/A & 214 & Melt & N/A & 0.05 & N/A & 0.014 & 0.0 \\
\hline 100.0 & 154 & 923 & 68 & 837 & N/A & 837 & Melt & N/A & 0.18 & N/A & 0.012 & 0.9 \\
\hline
\end{tabular}


The evaporative energy flux is the determining energy flux for this sample study, as the convective and kinetic energy fluxes remain constant. This is the determining flux because varying humidity controls the evaporative potential. In addition, the total wet bulb temperature, $T w b_{0}$, which is the balance between evaporative and convective energy fluxes, is a good indicator for determining freeze or melt-dominated icing for this sample (with no conduction). When $T w b_{0}$ is below freezing, freeze-dominated icing exists, whereas melt-dominated icing exists when $T w b_{0}$ is above freezing. There is a small exception in this case as can be seen when $R H_{s}=85.7 \%$. Melt-dominated icing exists, yet $T w b_{0}=-0.3^{\circ} \mathrm{C}$, which is below freezing. The reason for this is the contribution from the kinetic energy flux, which contributes a small amount of energy. If velocities were higher, this kinetic energy flux would be greater, and meltdominated icing would occur at even lower $T w b_{0}$ values. Conduction from the airfoil (wall) was not considered in this sample study, however, if the airfoil were heated and contributing energy into the icing surface, the melt-dominated icing would occur at even lower $T w b_{0}$ values.

\section{B. Model Evaluation with Experimental Data}

For this model evaluation, test conditions and ice growth rates are taken from two NASA published papers. The first paper presents findings and data on icing from tests that were conducted at the NRC RATFac icing wind tunnel in 2012. ${ }^{4}$ The second dataset used is from a test series conducted in 2016 at the NASA PSL icing wind tunnel. ${ }^{7}$ Both papers provide leading edge ice accretion data on a NACA 0012 airfoil with a $0.267 \mathrm{~m}$ (10.5 in) chord. Icing tests were performed at various velocities, pressures, temperatures, humidities, water contents, melt ratios, and cloud particle sizes. For more information on the description of the test facilities and experiments, please read the references provided.

Table 3 shows the measured test conditions just forward of the airfoil leading edge as the icing cloud is activated, including ice growth rates and airfoil temperatures, for select tests run during the two test series. The ice growth rates listed in the table are the reported rates at the centerline and leading edge of the airfoil. From Table 3 , $t_{\text {trans }}$ is the transient time period at the start of every test, during which the transient ice growth rate, $\dot{t}_{\text {trans }}$, was measured. In addition, $\dot{t}_{S S}$ is the steady-state ice growth rate measured during 120 and $180 \mathrm{~s}$ of spray time. The initial leading edge airfoil temperature at the midspan, $T_{\text {wall }, i}$, and the final temperature at the end of the test, $T_{\text {wall,e}}$, are listed as well. These values were measured by a thermocouple embedded at the leading edge of the airfoil midspan. The value of $T_{\text {wall,i }}$ at the airfoil leading edge can also be approximated as the total air temperature prior to spray activation (this pre-spray total air temperature is not listed in the Table 3 ). All tests began with an airfoil temperature measuring several degrees above freezing. It should be noted for clarity that total conditions are provided in Table 3, but several of the energy expressions provided utilize static conditions.

Table 3: Test conditions, ice growth rates, and airfoil leading edge thermocouple temperatures for select tests run during the 2012 NRC RATFac and 2016 NASA PSL test series. Thermocouple temperatures marked with $\mathrm{a}^{\dagger}$ symbol may have been reading $1.3^{\circ} \mathrm{C}$ high.

\begin{tabular}{|c|c|c|c|c|c|c|c|c|c|c|c|c|}
\hline \begin{tabular}{|c|} 
Test run \\
no.
\end{tabular} & $\begin{array}{l}U, \\
\mathrm{~m} / \mathrm{s}\end{array}$ & $\begin{array}{l}T_{0,}, \\
{ }^{\circ} \mathrm{C}\end{array}$ & $\begin{array}{l}p_{0}, \\
\mathrm{kPa}\end{array}$ & $\begin{array}{c}R H_{0}, \\
\%\end{array}$ & $\begin{array}{c}T w b_{0}, \\
{ }^{\circ} \mathrm{C}\end{array}$ & $\begin{array}{l}T W C, \\
\mathrm{~g} / \mathrm{m}^{3}\end{array}$ & $M R$ & $\begin{array}{l}\text { trrans, } \\
\mathrm{s}\end{array}$ & $\begin{array}{l}\dot{t}_{\text {trans }}, \\
\mathrm{mm} / \mathrm{s}\end{array}$ & $\begin{array}{c}\dot{t}_{S S} \\
\mathrm{~mm} / \mathrm{s}\end{array}$ & $\begin{array}{c}T_{\text {wall }, i}, \\
{ }^{\circ} \mathrm{C}\end{array}$ & $\begin{array}{l}T_{\text {wall,e, }}, \\
{ }^{\circ} \mathrm{C}\end{array}$ \\
\hline \multicolumn{13}{|c|}{2012 NRC RATFac } \\
\hline 796 & 86 & 7.2 & 44.8 & 41 & -0.1 & 5.54 & 0.12 & 0 to 20 & 0.056 & 0.016 & 13.3 & $1.3 \dagger$ \\
\hline 802 & 86 & 7.5 & 44.8 & 35 & -0.7 & 5.76 & 0.06 & 0 to 6.5 & 0.140 & 0.013 & 13.7 & $1.3 \dagger$ \\
\hline 824 & 86 & 6.0 & 44.8 & 40 & -1.0 & 5.82 & 0.05 & 0 to 6 & 0.101 & 0.003 & 11.4 & $1.0 \dagger$ \\
\hline 834 & 86 & 7.3 & 44.8 & 41 & -0.1 & 5.72 & 0.09 & 0 to 6 & 0.138 & 0.018 & 13.6 & $1.3 \dagger$ \\
\hline 849 & 136 & 9.0 & 44.8 & 53 & 3.4 & 9.24 & 0.15 & 0 to 6 & 0.180 & 0 & 13.3 & $1.3 \dagger$ \\
\hline 867 & 134 & 9.1 & 27.4 & 48 & 1.7 & 9.13 & 0.14 & 0 to 6 & 0.170 & 0.007 & 17.7 & $1.2 \dagger$ \\
\hline \multicolumn{13}{|c|}{2016 NASA PSL } \\
\hline 139 (“b”) & 82 & 2.6 & 44.5 & 22 & -6.0 & 3.16 & 0.13 & $\begin{array}{c}0 \text { to } 9 \\
9 \text { to } 20\end{array}$ & $\begin{array}{l}0 \\
0.082\end{array}$ & 0.026 & 6.0 & -3.7 \\
\hline 127 (“c”) & 82 & 2.6 & 44.5 & 44 & -3.3 & 3.84 & 0.31 & 0 to 20 & 0 & 0.024 & 6.0 & 0.0 \\
\hline 118 (“d”) & 83 & 3.1 & 44.5 & 47 & -2.6 & 3.87 & 0.38 & 0 to 20 & 0 & 0.026 & 6.0 & 0.0 \\
\hline 121 (“e”) & 81 & 3.5 & 44.6 & 61 & -0.7 & 4.70 & 0.87 & 0 to 20 & 0 & 0 & 5.8 & 0.0 \\
\hline
\end{tabular}


For the tests conducted at NRC RATFac, the first four entries of Table 3 were run at $86 \mathrm{~m} / \mathrm{s}$, and at $T w b_{0}$ values near $0{ }^{\circ} \mathrm{C}$. The final two entries in that test series were run at elevated velocities of about $135 \mathrm{~m} / \mathrm{s}$, and warmer conditions, where $T w b_{0}$ was above $0{ }^{\circ} \mathrm{C}$. The melt ratios are slightly different for each case, but fairly close in value. Also, final temperatures for this series of tests are marked with ${ }^{\dagger}{ }^{\dagger}$ symbol. Icing occurred at the leading edge for all six NRC RATFac tests, which would suggest that the measured thermocouple temperatures at the leading edge would read $0{ }^{\circ} \mathrm{C}$, however the recorded temperatures read about $1.3^{\circ} \mathrm{C}$. It is not clear why this leading edge thermocouple did not measure $0{ }^{\circ} \mathrm{C}$, but it is possible that an offset of $1.3^{\circ} \mathrm{C}$ exists in the reading.

The series of tests run at NASA PSL represents a plenum relative humidity sweep. For these tests, the conditions prior to the spray bar in the tunnel plenum were maintained as constant, however, as it has been previously observed and reported, the conditions downstream at the test section change with the activation of the spray cloud., Modeling efforts ${ }^{18-20}$ show that a thermodynamic interaction between the cloud and flowing air results in changes in air temperature and humidity at the test section, compared with pre-spray conditions. In addition, changes have been observed in total water content, melt ratio and cloud particle size, as compared with initial spray conditions. Whereas only humidity content was varied at the tunnel inlet (plenum), other parameters changed, most notably $T_{0}, T w b_{0}, M R$, and TWC. The ideal situation where only one variable is changed is not possible with this data. The four NASA PSL tests are also referenced in the paper as tests "b", "c", "d", and "e".

Model results for the select tests are provided in Table 4. The table includes individual energy fluxes and other model parameter results. Since conduction is relevant in the initial transient ice accretion period, the right-hand side of Eq. (1), $q_{R H S}^{\prime \prime}$, represents the total of evaporative, convective, kinetic energy, and conductive energy fluxes. The variable $t_{\text {cond } \rightarrow 0}$ in Table 4 represents the time for the conductive heat flux value to reach $1 \%$ of the total energy fluxes. This time represents when the conductive heat flux is negligible, and according to the model, marking the end of the transient ice accretion. This value is determined using the running average curve in Fig. 4 and finding the corresponding time with respect to the $1 \%$ of the total energy value (normalized by $T_{\text {wall }, i}$ ). The following model analysis is broken into four sections, representing the combinations of transient and steady-state ice growth during the 2012 NRC RATFac and 2016 NASA PSL test series. The following analysis toggles between data and calculations in Tables 3 and 4.

\section{2012 NRC RATFac Transient Analysis}

The transient ice growth rates were measured during the first $\sim 6 \mathrm{~s}$ of the test, except for Test Run no. 796 (TR no. for short) where $t_{\text {trans }}=20 \mathrm{~s}$. The conductive heat flux provided a significant amount of energy, resulting in meltdominated icing for all tests during the initial transient period. The value of the conductive heat flux is approximately an order greater than the other energy fluxes. The initial airfoil temperature was $11^{\circ} \mathrm{C}$ or more for all tests, which resulted in a significant amount of energy that was conducted to the impinging mixed-phase cloud. The calculated melt fraction values ranged from $m_{0}=0.34$ to 0.40 and mass loss fraction ranged between $n_{\text {loss }}=0.55$ and 0.82 . Finally, the time for the conductive heat flux to become negligible ranged between $t_{c o n d \rightarrow 0}=22$ and $31 \mathrm{~s}$. This generally correlates well with what was observed experimentally. Only the initial transient rates are provided for the first $\sim 6 \mathrm{~s}$, however, true steady-state ice accretion growth rates were generally not observed until at least 20 to $30 \mathrm{~s}$ after cloud activation. The ice growth rate changed continuously during this transition 20 to 30 s period. It is important to note that the reported transient ice growth rate values, $\dot{t}_{\text {trans }}$, capture a single growth rate for a period where there are continuously changing growth rates.

\section{2012 NRC RATFac Steady-State Ice Growth Analysis}

During the steady-state growth analysis, the conductive heat flux is set to zero, since $\dot{t}_{S S}$ values were calculated between 120 to $180 \mathrm{~s}$ into the icing test, well beyond the initial transition period where conduction was a factor. It can be seen that most tests were still melt-dominated icing. Only TR no. 824 transitioned from initial melt-dominated icing to freeze-dominated icing during the steady-state growth period. The mass loss fraction for all six of these tests ranged from $n_{\text {loss }}=0.96$ to 0.99 , significantly higher than the mass loss fraction values for the corresponding transient analysis. Inspecting the melt-dominated tests more closely (TR no. 796, 802, 834, 849, and 867), the mass loss fraction is lower for the three slower velocity tests compared with the two higher velocity tests ( $n_{\text {loss }} \sim 0.96$ vs. $\left.n_{\text {loss }} \sim 0.99\right)$. This intuitively makes sense as more erosion, bounce, runback, and splash would be expected at higher velocities. 
Table 4: Model results for select tests run during the 2012 NRC RATFac and 2016 NASA PSL test series. Energy values are listed according to sign notation of Eq. (1) if freeze dominated or Eq. (2) if melt dominated. $m_{0}$ and $n_{\text {loss }}$ values marked with a ${ }^{\ddagger}$ symbol have multiple (infinite) solutions.

\begin{tabular}{|c|c|c|c|c|c|c|c|c|c|c|c|c|}
\hline $\begin{array}{c}\text { Test run } \\
\text { no. }\end{array}$ & $\begin{array}{l}q_{\text {evap }}^{\prime \prime}, \\
\mathrm{W} / \mathrm{m}^{2}\end{array}$ & $\begin{array}{l}q_{\text {conv }}^{\prime \prime}, \\
W / \mathrm{m}^{2}\end{array}$ & $\begin{array}{l}q_{\text {kinetic }}^{\prime \prime}, \\
\mathrm{W} / \mathrm{m}^{2}\end{array}$ & $\begin{array}{l}\bar{q}_{\mathrm{cond}}^{\prime \prime}, \\
\mathrm{W} / \mathrm{m}^{2}\end{array}$ & $\begin{array}{l}q_{R H S}^{\prime \prime}, \\
\mathrm{W} / \mathrm{m}^{2}\end{array}$ & $\begin{array}{l}q_{\text {freeze }}^{\prime \prime}, \\
\mathrm{W} / \mathrm{m}^{2}\end{array}$ & $\begin{array}{l}q_{m e l t}^{\prime \prime}, \\
W / m^{2}\end{array}$ & \begin{tabular}{|c|}
$\begin{array}{c}\text { Condition, } \\
\text { melt/ } \\
\text { freeze }\end{array}$ \\
\end{tabular} & $n_{0}$ & $m_{0}$ & $n_{\text {loss }}$ & $\begin{array}{l}t_{\text {cond } \rightarrow 0,} \\
\quad \mathrm{~s}\end{array}$ \\
\hline \multicolumn{13}{|c|}{2012 NRC RATFac-Transient } \\
\hline 796 & 1,948 & 2,618 & 327 & 7,710 & 8,708 & N/A & 8,708 & Melt & N/A & 0.34 & 0.82 & 28 \\
\hline 802 & 2,516 & 2,720 & 768 & 21,789 & 22,760 & N/A & 22,760 & Melt & $\mathrm{N} / \mathrm{A}$ & 0.35 & 0.58 & 31 \\
\hline 824 & 2,395 & 2,177 & 586 & 19,233 & 19,601 & N/A & 19,601 & Melt & N/A & 0.39 & 0.68 & 31 \\
\hline 834 & 1,950 & 2,648 & 806 & 22,944 & 24,447 & N/A & 24,447 & Melt & N/A & 0.37 & 0.55 & 28 \\
\hline 849 & 223 & 3,927 & 2,716 & 22,438 & 28,858 & N/A & 28,858 & Melt & N/A & 0.34 & 0.76 & 22 \\
\hline 867 & 829 & 3,141 & 2,735 & 29,861 & 34,908 & N/A & 34,908 & Melt & N/A & 0.40 & 0.75 & 25 \\
\hline \multicolumn{13}{|c|}{2012 NRC RATFac_-Steady-State Ice Growth } \\
\hline 796 & 1,948 & 2,618 & 71 & 0 & 741 & N/A & 741 & Melt & N/A & 0.13 & 0.96 & $\mathrm{~N} / \mathrm{A}$ \\
\hline 802 & 2,516 & 2,719 & 49 & 0 & 252 & N/A & 252 & Melt & N/A & 0.06 & 0.97 & $\mathrm{~N} / \mathrm{A}$ \\
\hline 824 & 2,395 & 2,177 & 11 & 0 & 207 & 50 & N/A & Freeze & 1.00 & N/A & 0.99 & $\mathrm{~N} / \mathrm{A}$ \\
\hline 834 & 1,950 & 2,648 & 76 & 0 & 773 & N/A & 773 & Melt & N/A & 0.12 & 0.96 & N/A \\
\hline 849 & 223 & 3,927 & 124 & 0 & 3,828 & N/A & 3,828 & Melt & N/A & $1.00^{\ddagger}$ & $0.99^{\ddagger}$ & N/A \\
\hline 867 & 829 & 3,141 & 144 & 0 & 2,455 & N/A & 2,455 & Melt & N/A & 0.54 & 0.99 & N/A \\
\hline \multicolumn{13}{|c|}{2016 NASA PSL—Transient } \\
\hline $\begin{array}{c}139 \\
\text { (0 to } 9 \mathrm{~s})\end{array}$ & 4,471 & 922 & 45 & 7,352 & 3,849 & N/A & 3,849 & Melt & N/A & $1.00^{\ddagger}$ & $0.95^{\ddagger}$ & 20 \\
\hline $\begin{array}{c}139 \\
\text { (9 to } 20 \mathrm{~s} \text { ) }\end{array}$ & 4,471 & 922 & 257 & 310 & 2,982 & 2,982 & N/A & Freeze & 0.91 & N/A & 0.71 & 20 \\
\hline 127 & 2,808 & 923 & 24 & 3,478 & 1,617 & N/A & 1,617 & Melt & N/A & $1.00^{\ddagger}$ & $0.98^{\ddagger}$ & 22 \\
\hline 118 & 2,456 & 1,106 & 36 & 3,478 & 2,164 & N/A & 2,164 & Melt & N/A & $1.00^{\ddagger}$ & $0.97^{\ddagger}$ & 23 \\
\hline 121 & 1,211 & 1,237 & 281 & 3,363 & 3,669 & N/A & 3,669 & Melt & N/A & $1.00^{\ddagger}$ & $0.78^{\ddagger}$ & 36 \\
\hline \multicolumn{13}{|c|}{2016 NASA PSL—Steady-State Ice Growth } \\
\hline 139 & 4,471 & 922 & 80 & 0 & 3,468 & 1,032 & N/A & Freeze & 1.00 & N/A & 0.91 & N/A \\
\hline 127 & 2,808 & 923 & 81 & 0 & 1,804 & 1,804 & N/A & Freeze & 0.73 & N/A & 0.92 & N/A \\
\hline 118 & 2,456 & 1,106 & 112 & 0 & 1,238 & 1,238 & N/A & Freeze & 0.30 & N/A & 0.90 & N/A \\
\hline 121 & 1,211 & 1,237 & 2 & 0 & 28 & N/A & 28 & Melt & N/A & $1.00^{\ddagger}$ & $0.998^{\ddagger}$ & $\mathrm{N} / \mathrm{A}$ \\
\hline
\end{tabular}

$T R$ no. 824 was run with the coldest total wet-bulb temperature of $T w b_{0}=-1.0^{\circ} \mathrm{C}$ and is the main reason why this test resulted in freeze-dominated icing during the steady-state growth period. The freeze fraction for $T R$ no. 824 was $n_{0}=1.0$, which means that all of the liquid water that impinged the surface froze (after any mass loss). All this liquid water froze because of the below freezing $T w b_{0}$, a negligible kinetic energy flux contribution, and an initially low melt ratio of $M R=0.05$. Also noteworthy for $T R$ no. 824 is that the final wall temperature was lowest in the group, with $T_{\text {wall,e }}=1.0^{\circ} \mathrm{C}$. As noted before, there may exist a shift in thermocouple reading by $1.3^{\circ} \mathrm{C}$, which would suggest that the temperature at the ice and wall surface was below $0{ }^{\circ} \mathrm{C}$. The model suggests this was the case as $q_{R H S}^{\prime \prime}=207 \mathrm{~W} / \mathrm{m}^{2}$, which is greater than the latent heat of fusion surface flux value of $q_{\text {freeze }}^{\prime \prime}=50 \mathrm{~W} / \mathrm{m}^{2}$. As mentioned in the earlier sample case, when no more energy can be extracted from the latent energy phase change of water $\left(n_{0}=1.0\right)$, then sensible energy can be removed from the frozen ice. In other words, the ice has the potential to decrease in temperature below $0{ }^{\circ}$ C. For $T R$ no. 824, the mass loss fraction was high with $n_{\text {loss }}=0.99$. This high $n_{\text {loss }}$ can be intuitively expected with such a low melt ratio value and the high likelihood of particle bounce (and perhaps erosion) occurring.

$T R$ no. 796, 802, and 834 have reported total wet-bulb temperatures near $0{ }^{\circ} \mathrm{C}$, and with the contribution of the kinetic energy flux, these tests experienced melt-dominated icing. These three test runs, however, are near the melt 
and freeze threshold, in particular TR no. 802, as indicated by the low $q_{m e l t}^{\prime \prime}$ (and $q_{R H S}^{\prime \prime}$ ) values. With a low net energy flux slightly favoring melting, along with a large ratio of impinging ice (low $M R$ ), the resulting melt fraction was low as well $\left(m_{0}=0.06\right.$ to 0.13$)$.

$T R$ no. 867 was run at an elevated velocity of $134 \mathrm{~m} / \mathrm{s}$, with a total wet-bulb temperature above freezing, where $T w b_{0}=1.7^{\circ} \mathrm{C}$. This test run experienced the slowest ice growth of the melt-dominated ice accretion tests during the steady-state growth period. The elevated $T w b_{0}$ contributed to the high melt fraction $\left(m_{0}=0.54\right)$ calculated for this test. In fact, this melt fraction during steady-state growth is higher than the calculated transient melt fraction $\left(m_{0}=0.41\right)$.

$T R$ no. 849 is unique in this test set as there was effectively no growth beyond the initial ice accretion. There was a balance that was achieved between ice accretion and any mass loss mechanism in the steady-state growth period. It is not clear what physically happened for this sequence to transpire. With this test being the warmest, where $T w b_{0}=3.4^{\circ} \mathrm{C}$, any ice that was not lost may have fully melted, creating a zero ice growth rate during the steady-state period. This high melt capacity with the elevated $T w b_{0}$ condition does not, however, explain why there was initial ice growth when conductive heat from the airfoil only made it increasingly more likely to melt more ice. A possible mechanism is offered to explain the order of events. That is, perhaps the geometry was changed enough after initial accretion that with an ice shape that was now pointier in geometry than the initial blunt NACA 0012 leading edge, the mass loss increased leading to no further ice accretion, in particular for this higher velocity and $T w b_{0}$.

It should be noted that the steady-state ice growth rate for $T R$ no. 849 is $\dot{t}_{S S}=0 \mathrm{~mm} / \mathrm{s}$, and that the $m_{0}$ and $n_{\text {loss }}$ values are marked with an asterisks symbol, ${ }^{\ddagger}$. For tests with this symbol, this means that there are multiple (infinite) solutions. The values provided represent the minimum $n_{\text {loss }}$ value necessary for all remaining ice to fully melt ( $\left.m_{0}=1\right)$ in order to satisfy $\dot{t}_{S S}=0 \mathrm{~mm} / \mathrm{s}$. The other end of the solution set is $n_{\text {loss }}=1$, which results in a trivial value for $m_{0}$. There are an infinite number of solutions between these two solution bounds. These calculations for $\dot{t}_{\mathrm{SS}}=0 \mathrm{~mm} / \mathrm{s}$ would not be shown as they are trivial solutions, except that they provide thoroughness and help complete interpretations.

\section{2016 NASA PSL Transient Analysis}

Of the four test runs in this series, only TR no. 139 ("b") exhibited any ice growth in the first $20 \mathrm{~s}$. For the first $9 \mathrm{~s}$, no ice accreted on the airfoil, then ice accreted at a rate of $0.82 \mathrm{~mm} / \mathrm{s}$ from 9 to $20 \mathrm{~s}$, followed by ice growth at a steady-state beyond $20 \mathrm{~s}$, at a rate of $0.26 \mathrm{~mm} / \mathrm{s}$. For this case only, the transient period is broken into two periods, the first $9 \mathrm{~s}$ of no growth and the next $11 \mathrm{~s}$ where there was the fastest growth for the test. The transient values for TR no. 139 are split accordingly into two rows in Tables 3 and 4 . The value of $\bar{q}_{\text {cond }}^{\prime \prime}$, during the transient period where ice accreted, was calculated by taking the average of $\bar{q}_{\text {cond }}^{\prime \prime}$ from $t_{\text {trans }}=9$ to $20 \mathrm{~s}$, since the running average curve of Fig. 4 only applies for calculations starting at $t_{\text {trans }}=0 \mathrm{~s}$. Examining the results in Table 4, it can be seen that during the initial $9 \mathrm{~s}$, melt-dominated conditions existed, which then transitioned to freeze-dominated icing for the next $11 \mathrm{~s}$ of the transition period calculations. This suggests that the initially warm airfoil melted all ice (after losses) until the airfoil cooled enough, allowing for ice accretion. The reduced conductive heat flux to the ice during the later portion of the transition period aided ice accretion since the growth rate of $0.82 \mathrm{~mm} / \mathrm{s}$ was greater than the $0.26 \mathrm{~mm} / \mathrm{s}$ steady-state growth rate. Also, a lower mass loss fraction of $n_{\text {loss }}=0.71$ was calculated for the latter portion of the transient test, compared with the steady-state growth period of $n_{\text {loss }}=0.91$. In addition, according to the model, conductive heat flux is $1 \%$ of the total heat flux after $t_{c o n d \rightarrow 0}=20 \mathrm{~s}$, which is in line with what was measured experimentally.

Ice accretion for TR no. 127 (“c") and 118 (“d”) occurred only beyond $30 \mathrm{~s}$ of cloud activation, and TR no. 121 ("e") did not accrete any ice at any point in the test. Whereas no ice accreted during the initial transient period for these three tests, all fall under the melt-dominated regime due to the high conductive heat flux contribution. Again, an infinite number of solutions exist for tests where $\dot{t}_{\text {trans }}=0 \mathrm{~mm} / \mathrm{s}$, but Table 4 provides minimum $n_{\text {loss }}$ values necessary for all remaining ice to fully melt $\left(m_{0}=1\right)$. Conductive heat flux became negligibly small between $t_{\text {cond } \rightarrow 0}=22$ and 36 s. Again, these times generally correlate well with what was observed experimentally as steady-state ice growth occurred beyond $30 \mathrm{~s}$ after spray activation.

\section{2016 NASA PSL Steady-State Ice Growth Analysis}

Freeze-dominated icing occurred for the three tests where there was ice accretion during the steady-state growth period. The mass loss fraction ranged from $n_{\text {loss }}=0.90$ to 0.92 . In addition, the freeze fraction decreased as total wet-bulb temperatures increased $\left(T w b_{0}=-6.0\right.$ to $\left.-2.6{ }^{\circ} \mathrm{C}\right)$ for these tests. This is expected as the magnitude of the 
evaporative heat flux is reduced with increasing total relative humidity (increasing $T w b_{0}$ ), reducing the amount of water that could freeze to ice. This decreasing freeze fraction is also compounded with the fact that there is more water (higher $M R$ ) to freeze for the higher $T w b_{0}$ tests. Eventually, as total relative humidity is increased even further in $T R$ no. 121, the condition becomes melt dominated. As previously mentioned, no ice accretion occurred at all for $T R$ no. 121 . The high melt ratio value of $M R=0.87$ likely contributed to the high $n_{\text {loss }}$ value via splashing and runback.

$T R$ no. 139 ("b") provides some interesting insight. With a low total wet-bulb temperature $\left(T w b_{0}=-6.0^{\circ} \mathrm{C}\right)$ and low melt ratio $(M R=0.13)$, all liquid water that impinged (after losses) froze, as indicated by the freeze fraction of $n_{0}=1$. Looking at the energy fluxes for this test in Table 4, the model suggests sensible energy loss from the ice mass can occur as $q_{R H S}^{\prime \prime}=3,468 \mathrm{~W} / \mathrm{m}^{2}$, which is greater than the latent heat of fusion surface flux value of $q_{\text {freeze }}^{\prime \prime}=1,032 \mathrm{~W} / \mathrm{m}^{2}$. Indeed, the final temperature as recorded by the leading edge thermocouple at the airfoil midspan measured $T_{\text {wall,e }}=-3.7^{\circ} \mathrm{C}$. This was the only test in this series suggesting sensible energy loss and the only test that measured a temperature other than $T_{\text {wall, } e}=0^{\circ} \mathrm{C}$.

\section{Discussion}

This section presents information related to the topics of incorporation of the transient conduction model, steady-state ice growth, comparing mass loss fraction when ice accretion occurred, and how the thermodynamic model relates to how icing facilities generate mixed-phase clouds. Incorporating the transient conduction model has allowed for a greater understanding of the physical phenomena that occurred during the initial moments of each icing test. With an initially warm airfoil, energy was conducted from the airfoil to the ice, and in general created a more melt-dominated condition at the onset of the test. Several tests transitioned from initial melt-dominated conditions, to freeze-dominated conditions as the airfoil cooled and reached a steady-state temperature. According to the model, it took on the order of 20 to $30 \mathrm{~s}$ for the conductive heat flux to become negligible, which matches well with what was observed experimentally. These conductive values were calculated for an airfoil with a particular shell thickness, material physical properties, and initial temperature. An initially hotter and fully solid airfoil with all else being constant, for example, would exhibit different conductive behavior, supplying more heat to melt more ice, and prolonging the transient period. An initially cold airfoil that is below freezing, for example, would be favorable to freeze-dominated icing as more liquid water would freeze initially.

Looking at steady-state ice growth only, calculations of $n_{\text {loss }}$ suggest that over $90 \%$ of the impinging water and ice mass is lost to splash, runback, bounce, and erosion. Whereas there are several variables that differ within this group of 10 test cases, a peak in water mass retention with respect to melt ratio appears to exist. The value of $n_{\text {loss }}$ is slightly greater for very low melt ratio cases $\left(n_{\text {loss }} \sim 0.96\right)$, decreases slightly for mid-value melt ratios $\left(n_{\text {loss }} \sim 0.91\right)$, then increases again when the melt ratios are high $\left(n_{\text {loss }} \sim 1.0\right)$. This trend gives credence to previous research work that theorized that an optimum icing regime exists for ice crystal icing as a function of melt ratio. The hypothesis states that icing will not occur if there is not enough ice to cool the surface to the freezing point and where there is not enough liquid for the ice to stick. ${ }^{2}$ The model results from the steady-state ice growth analysis suggest that at a low $M R$, the value of $n_{\text {loss }}$ is higher from a combination of more ice crystal bounce and erosion. Similarly, high values of $n_{\text {loss }}$ occur at high $M R$ values due to a combination of splash and runback. Note that this is a very limited dataset.

In comparing the mass loss fraction when ice accretion occurred, $n_{\text {loss }}$ is lower during the initial transient with an initially warm airfoil as compared with the steady-state growth period where the airfoil had cooled in temperature. This difference is clear in the NRC RATFac studies and TR no. 139 from the NASA PSL test series when looking at Table 4. A greater amount of liquid water existed on the surface during the initial transient, due to the additional melt created from conductive heat flux. This created a wet, sticky surface, which was likely the physical mechanism that allowed more of the incoming cloud to be captured, reducing $n_{\text {loss. }}$. There exists a limit, however, as can be seen by the three higher $M R$ tests in the NASA PSL test series where there was likely too much liquid water, and no ice accretion occurred during the initial transient period. This reinforces the point that there likely exists an optimum liquid water content at the surface to achieve the greatest ice growth rate. This optimal liquid water content regime for maximum ice accretion is not only dependent on the melt ratio, but also the balance of energy fluxes at the icing surface.

It should be noted that in order to produce a mixed-phase cloud at the NASA PSL facility, a liquid water cloud was sprayed and then partially froze as the cloud approached the test section. Water droplets partially froze by losing sensible and latent energy through a combination of evaporative cooling and convective heat transfer to the cold air. ${ }^{21}$ This is the exact opposite order of generating a mixed-phase cloud that occurred at the NRC RATFac. At the RATFac, ice particles were sprayed and melted as the ice cloud approached the test section. ${ }^{22}$ Ice particles passed through an injection duct and mixed with warmer, humid air entering the wind tunnel. Convective heat transfer from the warm air aids in partially melting the ice cloud, whereas higher water vapor levels minimized evaporative cooling. The 
requirements of producing mixed-phase clouds at each facility can be recognized in the Condition column of Table 4 in the steady-state ice growth analysis. To generate mixed-phase clouds at the PSL, the liquid spray cloud had to be partially frozen, and this is evident because all steady-state ice growth was freeze-dominated icing. To generate mixed-phase clouds at the RATFac, the ice cloud had to be partially melted, and again this is apparent because nearly all steady-state ice growth was melt-dominated icing.

This analysis has shown that a conduction term is an important addition to Tsao et al.'s model ${ }^{12}$ to more accurately capture the fundamental thermodynamic energy exchanges occurring at the icing surface. Also, in the evaluation of the model, high values of mass loss fractions exceeding 0.90 have been calculated for the steady-state ice growth period. Furthermore, this analysis suggests that optimal conditions for icing exist that are dependent on the melt ratio and the balance of energy fluxes at the icing surface. Lastly, this study suggests that for experimental icing tests that have been conducted at ground facilities, how the ice was formed may need to be considered when assessing icing results.

\section{Conclusions}

This paper builds on Tsao et al.'s proposed thermodynamic icing model that was developed to explain the mechanism of ice crystal icing that occurs within the core of jet engines. A transient conductive heat flux term was added to the model's energy balance to help explain icing behavior that occurred early in the onset of an icing cloud during experimental tests. The model, in addition to the modification, was evaluated against experimental ice accretion data that was measured during tests conducted at the National Aeronautics and Space Administration (NASA) Propulsion Systems Laboratory (PSL) icing wind tunnel in 2016 and at the National Research Council (NRC) of Canada Research Altitude Test Facility (RATFac) icing wind tunnel in 2012.

The model provided key insights into previously unknown values related to icing, which include mass loss fraction, melt fraction, and freeze fraction. During steady-state ice growth, values of mass loss fraction were 0.90 and greater. With an initial airfoil temperature several degrees warmer than freezing, the conductive heat flux affected ice accretion behavior such that the mass loss fraction was reduced compared with the steady-state ice growth values. The model suggests that optimal liquid water contents exist to achieve greater ice accretion rates. Values of mass loss fraction, $n_{\text {loss }}$, were greatest when there were little amounts (low melt ratio) and a large amounts (high melt ratio) of liquid water, and the lowest $n_{\text {loss }}$ values occurred when there was a moderate amount of liquid water. This optimal liquid water content regime for maximum ice accretion is dependent on the melt ratio and the balance of energy fluxes at the icing surface.

Calculations show that the conductive heat flux term can dominate in the initial moments of an icing test, in particular when the initial airfoil temperature is several degrees away from $0{ }^{\circ} \mathrm{C}$, like it was in this evaluation. Given the airfoil geometry and conditions, according to the model, the conduction effect diminished after 20 to $30 \mathrm{~s}$, which is in line with what was observed experimentally. After this initial transient state, the total wet-bulb temperature provided a good indication of which type of icing will occur. In general for steady-state ice growth, when total wet-bulb temperature was near of above $0{ }^{\circ} \mathrm{C}$, melt-dominated icing occurred, and when it was below $0{ }^{\circ} \mathrm{C}$, freeze-dominated icing occurred.

\section{Acknowledgments}

The authors wish to acknowledge the financial support for this work by the Advanced Aircraft Icing (AAI) subproject of the NASA Advanced Air Transport Technology Project (AATT) under NASA's, Advanced Air Vehicle's program.

\section{References}

\footnotetext{
${ }^{1}$ Mason, J. G., Strapp, J. W., and Chow, P., “The Ice Particle Threat to Engines in Flight,” 44th AIAA Aerospace Sciences Meeting and Exhibit, 2006-206, AIAA, Reston, VA, 2006. doi: 10.2514/6.2006-206.

${ }^{2}$ Mason, J. G., Chow, P., and Fuleki, D. M., "Understanding Ice Crystal Accretion and Shedding Phenomenon in Jet Engines Using a Rig Test,” Journal of Engineering for Gas Turbines and Power, Vol. 133, No. 4, 2010, pp. 041201-041201-8. doi: 10.1115/1.4002020.

${ }^{3}$ Struk, P. M., King, M. C., Bartkus, T. P., Tsao, J-C., Fuleki, D., Neuteboom, M., and Chalmers, J. L., "Ice Crystal Icing Physics Study Using a NACA 0012 Airfoil at the National Research Council of Canada's Research Altitude Test Facility,” 10th AIAA Atmospheric and Space Environments Conference, AIAA, Reston, VA, 2018 (submitted for publication).
} 
${ }^{4}$ Struk, P. M., Bartkus, T. P., Tsao, J. C., Currie, T., and Fuleki, D., "Ice Accretion Measurements on an Airfoil and Wedge in Mixed-Phase Conditions," SAE 2015 International Conference on Icing of Aircraft, Engines, and Structures, SAE International, Warrendale, PA, 2015. doi: 10.4271/2015-01-2116.

${ }^{5}$ Currie, T. C., Struk, P. M., Tsao, J., Fuleki, D., and Knezevici, D. C. "Fundamental Study of Mixed-Phase Icing with Application to Ice Crystal Accretion in Aircraft Jet Engines," 4th Atmospheric and Space Environments Conference, AIAA, Reston, VA, 2012. doi: 10.2514/6.2012-3035.

${ }^{6}$ Struk, P. M., Broeren, A. P., Tsao, J-C., Vargas, M., Wright, W. B., Currie, T., Knezevici, D., and Fuleki, D., "Fundamental Ice Crystal Accretion Physics Studies,” SAE 2011 International Conference on Aircraft and Engine Icing and Ground Deicing, NASA/TM-2012-217429, 2011. doi: 10.4271/2011-38-0018.

${ }^{7}$ Struk, P. M., Ratvasky, T. P., Bencic, T., Van Zante, J. F., King, M. C., Tsao, J.-C., and Bartkus, T. P., “An Initial Study of the Fundamentals of Ice Crystal Icing Physics in the NASA Propulsion Systems Laboratory," 9th AIAA Atmospheric and Space Environments Conference, 2017-4242, AIAA, Reston, VA, 2017. doi: 10.2514/6.2017-4242.

${ }^{8}$ Currie, T. C., Fuleki, D., and Mahallati, A. "Experimental Studies of Mixed-Phase Sticking Efficiency for Ice Crystal Accretion in Jet Engines," 6th AIAA Atmospheric and Space Environments Conference, 2014-3049, AIAA, Reston, VA, 2014. doi: 10.2514/6.2014-3049.

${ }^{9}$ Currie, T. C., Fuleki, D., Knezevici, D. C., and MacLeod, J. D. “Altitude Scaling of Ice Crystal Accretion,” 5th AIAA Atmospheric and Space Environments Conference, 2013-2677, AIAA, Reston, VA, 2013. doi: 10.2514/6.2013-2677.

${ }^{10}$ Knezevici, D. C., Fuleki, D., Currie, T. C., Galeote, B., Chalmers, J., and MacLeod, J. D. “Particle Size Effects on Ice Crystal Accretion - Part II,” 5th AIAA Atmospheric and Space Environments Conference, 2013-2676, AIAA, Reston, VA, 2013. doi: 10.2514/6.2013-2676.

${ }^{11}$ Knezevici, D. C., Fuleki, D., Currie, T. C., and MacLeod, J. D. "Particle Size Effects on Ice Crystal Accretion," 4th AIAA Atmospheric and Space Environments Conference, 2012-3039, AIAA, Reston, VA, 2012. doi: 10.2514/6.2012-3039.

${ }^{12}$ Tsao, J-C., Struk, P. M., and Oliver, M. J., "Possible Mechanisms for Turbofan Engine Ice Crystal Icing at High Altitude," 6th AIAA Atmospheric and Space Environments Conference, 2014-3044, AIAA, Reston, VA, 2014. doi: 10.2514/6.2014-3044.

${ }^{13}$ Ruff, G. A., “Analysis and Verification of the Icing Scaling Equations,” AEDC-TR-85-30, Vol. 1 (Rev), 1986.

${ }^{14}$ Anderson, D. N., “Manual of Scaling Methods,” NASA/CR-2004-212875, 2004.

${ }^{15}$ Anderson, D. N., and Tsao, J.-C., "Ice Shape Scaling for Aircraft in SLD Conditions," NASA/CR-2008-215302, DOT/FAA/AR-07/55, 2008.

${ }^{16}$ Rigby, D. L., Struk, P. M., and Bidwell, C. S., "Simulation of Fluid Flow and Collection Efficiency for an SEA Multi-Element Probe,” 6th AIAA Atmospheric and Space Environments Conference, 2014-2752, AIAA, Reston, VA, 2014. doi: 10.2514/6.20142752.

${ }^{17}$ Kreyszig, E., Advanced Engineering Mathematics, $8^{\text {th }}$ ed., John Wiley \& Sons, Inc., New York, 1999, pp. 526-607.

${ }^{18}$ Bartkus, T. P., Struk, P. M., and Tsao, J-C., "Comparisons of Mixed-Phase Icing Cloud Simulations with Experiments Conducted at the NASA Propulsion Systems Laboratory,” 9th AIAA Atmospheric and Space Environments Conference. 2017-4243, AIAA, Reston, VA, 2017. doi: 10.2514/6.2017-4243.

${ }^{19}$ Bartkus, T. P., Struk, P. M., Tsao, J. C., and Van Zante, J. F., "Numerical Analysis of Mixed-Phase Icing Cloud Simulations in the NASA Propulsion Systems Laboratory,” 8th AIAA Atmospheric and Space Environments Conference, 2016-3739, AIAA, Reston, VA, 2016. doi: 10.2514/6.2016-3739.

${ }^{20}$ Bartkus, T. P., Struk, P. M., and Tsao, J. C., "Development of a Coupled Air and Particle Thermal Model for Engine Icing Test Facilities,” SAE International Journal of Aerospace, Vol. 8, No. 1, 2015, pp. 15-32. doi: 10.4271/2015-01-2155.

${ }^{21}$ Van Zante, J. F., Bencic, T. J., and Ratvasky, T. P., "Update on the NASA Glenn Propulsion Systems Lab Ice Crystal Cloud Characterization Update 2015,” 8th AIAA Atmospheric and Space Environments Conference, 2016-3897, AIAA, Reston, VA, 2016. doi: 10.2514/6.2016-3897.

${ }^{22}$ Knezevici, D. C., Fuleki, D., and MacLeod, J., "Development and Commissioning of the Linear Compressor Cascade Rig for Ice Crystal Research,” SAE 2011 International Conference on Aircraft and Engine Icing and Ground Deicing, SAE International, Warrendale, PA, 2011. doi: 10.4271/2011-38-0079. 